11 Bines JE, Winter HS. Lower endoscopy. Pediatric gastrointestinal diseases. Vol 2. In: Walker WA, Durie PR, Hamilton JR, Walker-Smith JA, Watkins JB, eds. Philadelphia: BC Decker, 1991: 1257-71.

12 Spigelman AD, Phillps RKS. Case report and management in Peutz-Jeghers polyps. $\mathcal{F} R$ Soc Med 1989; 82: 681 .

13 Cohen LB, Waye JD. Treatment of colonic polyps - practical considerations. Clinics in Gastroenterology 1986; 15: 359-76.
14 Jass JR, Williams CB, Bussey HJ, Morsen BC. Juvenile polyposis - a precancerous condition. Histopathology 1988; 13: $619-30$.

15 Giardiello FM, Hamilton SR, Kern SE, et al. Colorectal neoplasm in juvenile polyposis or juvenile polyps. Arch Dis Child 1991; 66: 971-3.

16 Williams CB, Laage NJ, Campbell CA, et al. Total colonoscopy in children. Arch Dis Child 1982; 57: 49-53.

\title{
Eczema and the yellow emperor
}

The principles of traditional Chinese herbal therapy (TCHT) were described in the Inner Classic of the Yellow Emperor which was written by our old friend, Anonymous, between 300 and $100 \mathrm{BC}$. Two recent papers have confirmed the effectiveness of such treatment in adults (Mary Sheehan and colleagues, Lancet 1992; 340: 13-7) and children (Mary Sheehan and David Atherton, British Fournal of Dermatology 1992; 126: 179-84).

It had been noted that some patients with eczema refractory to conventional treatment had been treated by a practitioner of TCHT in London with apparent success. It is almost impossible for Western physicians to give the full Chinese treatment because that varies from patient to patient, and from time to time in the same patient, depending on the TCHT practitioner's assessment of the pulse and the tongue as well as the features of the eczema. Dr Sheehan and her colleagues therefore settled for giving the herbal medicine as recommended by a Chinese medical practitioner of TCHT for use in a typical case of the particular type of eczema studied.

Forty seven children aged 18 months to 18 years were admitted to a double blind trial over a four month period. All had extensive nonexudative atopic eczema not confined to the flexures and characterised by a diffuse morbilliform or sclarlatiniform erythema usually more marked on the trunk than the limbs, and often with mild to moderate lichenification. No topical steroids were used during the study which lasted for 20 weeks and followed a double blind, placebo controlled, crossover design. Active treatment consisted of a decoction prepared from constituents of 10 plants obtained from bona fide suppliers in China. Placebo decoctions were made to have a similar appearance, taste, and smell but from herbs not thought to benefit eczema. The children were expected to drink about $100 \mathrm{ml}$ of warm decoction freshly made each day and, surprisingly, only five of them balked at it to the extent that they failed to complete the study (three active treatment, two placebo). Five others (one active treatment, four placebo) failed to complete the study because they were given either steroid treatment for asthma or an antibiotic for skin infection.

The children were assessed every four weeks using a standardised scoring system for erythema and skin surface damage. There appeared to be clear benefit during active treatment. The median percentage decrease in scores for erythema was $51 \%(34.5$ to $72.6 \%)$ during the active treatment phases and $6 \%(-25 \cdot 2$ to $30 \cdot 7 \%)$ on placebo, and for surface damage $63 \%(34.5$ to $72 \cdot 6 \%)$ during active treatment and $6 \%$ $(-25 \cdot 2$ to $30 \cdot 7 \%)$ on placebo. Of the 37 children completing the trial 19 were reported to have slept better on active treatment and three on placebo. When asked to say which phase of treatment was better the parents of 27 children identified the active treatment phase and of two the placebo phase. In eight cases the parents were unable to choose between the two phases. No toxicity was identified during the study but the authors point out that they have no information about long term toxicity.

How it works is not known but it does not appear to be a corticosteroid-like effect. The authors are cautiously optimistic about the potential value of the treatment and, although the trial was restricted to one form of severe eczema, they say that they have 'no reason to believe' that it would not be effective in other types.

Four cheers for Dr Ding-Hui Luo for her cooperation, say I. 